\title{
Breve panorama da judicialização da saúde no Brasil e os reflexos dos julgamentos dos recursos repetitivos pelos Tribunais Superiores
}

Brief overview of the judicialization of health in Brazil and the reflexes of repetitive appeals judgments by Higher Courts

Breve resumen de la judicialización de la salud en Brasil y los reflejos de juicios de apelaciones repetitivas de los Tribunales Superiores

Catarina de Sá Guimarães Ribeiro ${ }^{1}$

Cristina Câmara Wanderley Queiroz $^{2}$

\section{Resumo}

Objetivos: diante dos novos parâmetros estabelecidos nos recentes julgamentos de recursos repetitivos representativos de controvérsias em demandas de saúde pelos Tribunais Superiores pátrios, o estudo analisou o perfil de decisões das instâncias inferiores a partir desse fato. Métodos: foram analisadas as decisões proferidas pelo Judiciário pernambucano após a publicação das respectivas atas de julgamento no Diário de Justiça eletrônico, marco inicial da obrigatoriedade de observância das teses fixadas, conforme regramento do §11, do art. 1.035 do Código de Processo Civil. Resultados: os resultados demonstraram tímida mudanças na forma de resolução das demandas de saúde, com apego a velhas formas de decidir, sem aprofundamento da necessária discussão multidisciplinar que a questão exige. Discussão e conclusões: os resultados obtidos podem contribuir para alertar para a necessidade de resolução da judicialização da saúde de modo racional e alinhado com as teses vinculantes definidas pelas Cortes Superiores.

Palavras-chave: Direito à saúde. Judicialização da saúde. Poder Judiciário. Decisões judiciais.

\begin{abstract}
Objectives: in view of the new parameters established in the recent judgments of repetitive appeals that are representative of controversies in health demands by the Brazilian Supreme Court, the study analyzed the decision-making profile of the lower courts based on this fact. Methods: the judgments handed down by the Pernambuco Judiciary were analyzed after the publication of the respective minutes of judgment in the electronic Justice Gazette, the initial landmark of the obligation to observe the established theses, according to the rule of $\S 11$, art. 1.035 of the Code of Civil Procedure. Results: the results showed shy changes in the way health demands were resolved, with attachment to old ways of deciding, without deepening the necessary multidisciplinary discussion that the issue requires. Discussion and conclusions: the results obtained may contribute to alert to the need to resolve the

\footnotetext{
${ }^{1}$ Graduada em Direito pela Universidade Católica de Pernambuco; pós-graduada em Direito Sanitário pela Fiocruz Brasília; procuradora do Estado de Pernambuco. E-mail: catarinapge@gmail.com

2 Graduada em Direito pela Universidade Católica de Pernambuco; pós-graduada em Direito Sanitário pela Fiocruz Brasília; procuradora do Estado de Pernambuco. E-mail: cristina.queiroz@pge.pe.gov.br
} 
judicialization of health rationally and in line with the binding theses defined by the Superior Courts.

Keywords: Right to health. Health's judicialization. Judiciary. Judicial decisions.

\section{Resumen}

Objetivos: en vista de los nuevos parámetros establecidos en las sentencias recientes de apelaciones repetitivas que son representativas de controversias en demandas de salud por parte de la Corte Suprema, el estudio analizó el perfil de toma de decisiones de los tribunales inferiores con base en este hecho. Métodos: los juicios dictados por el Poder Judicial de Pernambuco se analizaron después de la publicación de las actas de juicio respectivas en la Gaceta de Justicia electrónica, el hito inicial de la obligación de observar las tesis establecidas, de acuerdo con la regla del §11, art. 1.035 del Código de Procedimiento Civil. Resultados: los resultados mostraron cambios tímidos en la forma en que se resolvieron las demandas de salud, con apego a las viejas formas de decidir, sin profundizar la necesaria discusión multidisciplinaria que requiere el tema. Discusión y conclusiones: los resultados obtenidos pueden contribuir a alertar sobre la necesidad de resolver la judicialización de la salud de manera racional y en línea con las tesis vinculantes definidas por los Tribunales Superiores.

Palabras clave: Derecho a la salud. Judicialización de la salud. Poder Judicial. Decisiones judiciales.

\section{Introdução}

Estamos na era do extremo ativismo judicial, não só nos temas de saúde pública. Seja em razão do aumento da consciência política e de cidadania do povo, seja ante a dificuldade dos Poderes Executivo e Legislativo de cumprirem os seus respectivos papéis constitucionais, o Judiciário revela-se como detentor da última e decisiva palavra na consecução da cidadania; e, obviamente, em toda situação extrema, a racionalidade e a razoabilidade não prevalecem (1).

Durante muitos anos o Judiciário entendeu que decidir sobre fornecimento de medicamentos era se imiscuir na seara do administrador público e refutava lides dessa natureza.

$\mathrm{Na}$ década de 1990, com o surgimento de novas tecnologias para tratamento da Síndrome de Imunodeficiência Adquirida (Sida), os magistrados foram instados a se manifestarem sobre o direito dos pacientes soropositivos ao acesso àquelas. Houve não só uma quebra de paradigma judicial, como se instituiu toda uma política pública de vanguarda no mundo (2).

$\mathrm{Na}$ última década, as ações de saúde se multiplicaram e, em muitos estados brasileiros, o Judiciário interfere sobremaneira nos orçamentos das secretarias de saúde, 
para atender a uma parcela muito pequena da população $(3,4)$. Surpreende o fato de essas lides versarem sobre tecnologias não incorporadas e sequer avaliadas pelos órgãos do Ministério da Saúde como a Agência Nacional de Vigilância Sanitária (Anvisa) e a Comissão Nacional de Incorporação de Tecnologia do Sistema Único de Saúde (Conitec) (4).

É possível ainda, em rápida pesquisa aos sítios os tribunais na internet, observar que boa parte das demandas visam a obtenção de tratamento para patologias com protocolos estabelecidos no Sistema Único de Saúde (SUS), como diabetes, sem falar nos tratamentos oncológicos, cuja decisão de descentralização da política pública através dos centros de tratamentos oncológicos foi decidida pela União Federal e por ela é custeada (5).

Essa avalanche de demandas vem causando transtornos, e inviabilidade muitas vezes, aos orçamentos e à administração da saúde pública, mas também se tornou um problema ao próprio Poder Judiciário que, sem qualquer aparato técnico, se viu, equivocadamente, com o aparente dilema da vida e da morte nas mãos (6).

Diante desse contexto, o artigo tem como objetivo analisar a influência das recentes teses fixadas pelas Cortes Superiores para o deslinde das questões relacionadas à judicialização da saúde em Pernambuco.

\section{O direito à saúde nos tribunais: alguns casos concretos}

Desde os anos 2000, um dos mais emblemáticos enfrentamentos dos Tribunais Superiores se deu na ocasião do Julgamento da Suspensão de Tutela Antecipada (STA) 175, quando o Ministro Relator, Gilmar Mendes, convocou uma audiência pública para ouvir especialistas sobre o assunto.

A partir de então, em decisão paradigmática, ${ }^{3}$ iniciou-se a definição de algumas balizas que puderam servir de guia para o Poder Judiciário nas demandas de saúde.

A primeira delas é a de que não se pode admitir o financiamento de toda e qualquer ação e prestação de saúde, devendo-se privilegiar o tratamento fornecido pelo SUS em detrimento de opção diversa escolhida pelo paciente:

(...) O segundo dado a ser considerado é a existência de motivação para o não fornecimento de determinada ação de saúde pelo SUS. Há casos em que se ajuíza ação com o objetivo de garantir prestação de saúde que o SUS

${ }^{3}$ STA-AgR 175 - apenso STA-AgR 178; SS-AgR 3724; SS-AgR 2944; SL-AgR 47; STA-AgR 278; SS-AgR 2361; SS-AgR 3345; SS-AgR 3355 
decidiu não custear por entender que inexistem evidências científicas suficientes para autorizar sua inclusão. Nessa hipótese, podem ocorrer, ainda, duas situações distintas: $\left.1^{\circ}\right)$ o SUS fornece tratamento alternativo, mas não adequado a determinado paciente; $2^{\circ}$ ) 0 SUS não tem nenhum tratamento específico para determinada patologia. A princípio, pode-se inferir que a obrigação do Estado, à luz do disposto no artigo 196 da Constituição, restringe-se ao fornecimento das políticas sociais e econômicas por ele formuladas para a promoção, proteção e recuperação da saúde. Isso porque o Sistema Único de Saúde filiou-se à corrente da "Medicina com base em evidências". Com isso, adotaram-se os "Protocolos Clínicos e Diretrizes Terapêuticas", que consistem num conjunto de critérios que permitem determinar o diagnóstico de doenças e o tratamento correspondente com os medicamentos disponíveis e as respectivas doses. Assim, um medicamento ou tratamento em desconformidade com o Protocolo deve ser visto com cautela, pois tende a contrariar um consenso científico vigente. Ademais, não se pode esquecer de que a gestão do Sistema Único de Saúde, obrigado a observar o princípio constitucional do acesso universal e igualitário às ações e prestações de saúde, só se torna viável mediante a elaboração de políticas públicas que repartam os recursos (naturalmente escassos) da forma mais eficiente possível. Obrigar a rede pública a financiar toda e qualquer ação e prestação de saúde existente geraria grave lesão à ordem administrativa e levaria ao comprometimento do SUS, de modo a prejudicar ainda mais o atendimento médico da parcela da população mais necessitada. Dessa forma, podemos concluir que, em geral, deverá ser privilegiado o tratamento fornecido pelo SUS em detrimento de opção diversa escolhida pelo paciente, sempre que não for comprovada a ineficácia ou a impropriedade da política de saúde existente. (13).

Outro parâmetro definido em decisão de Gilmar Mendes diz respeito à vedação de concessão de medicamento não registrado na Anvisa, por se tratar o registro de medicamento de uma garantia à saúde pública, admitindo como única exceção a previsão contida na Lei no 9.782/99 (7), que criou a Agência Nacional de Vigilância Sanitária ( Anvisa), que permite a dispensa pela agência de registro de medicamentos adquiridos por intermédio de organismos multilaterais internacionais, para uso de programas em saúde pública pelo ministério da saúde".

Neste sentido, vale transcrever a passagem da decisão proferida na SS 3989 - Piauí (07/04/2010) pelo Ministro Gilmar Mendes sobre o tema, verbis:

(...) Não raro, busca-se no Poder Judiciário a condenação do Estado ao fornecimento de prestação de saúde não registrada na Agência Nacional de Vigilância Sanitária (Anvisa). Como ficou claro nos depoimentos prestados na Audiência Pública, é vedado à Administração Pública fornecer fármaco que não possua registro na Anvisa. A Lei Federal n. ${ }^{\circ} 6.360 / 76$, ao dispor sobre a vigilância sanitária a que ficam sujeitos os medicamentos, as drogas, os insumos farmacêuticos e correlatos, determina em seu artigo 12 que "nenhum 
dos produtos de que trata esta Lei, inclusive os importados, poderá ser industrializado, exposto à venda ou entregue ao consumo antes de registrado no Ministério da Saúde". O artigo 16 da referida Lei estabelece os requisitos para a obtenção do registro, entre eles, que o produto seja reconhecido como seguro e eficaz para o uso a que se propõe. O Art. 18 ainda determina que, em se tratando de medicamento de procedência estrangeira, deverá ser comprovada a existência de registro válido no país de origem. O registro de medicamento, como lembrado pelo Procurador-Geral da República, é uma garantia à saúde pública. $\mathrm{E}$, como ressaltou o Diretor-Presidente da Anvisa, a agência, por força da lei de sua criação, também realiza a regulação econômica dos fármacos.

Após verificar a eficácia, segurança e qualidade do produto e conceder o registro, a Anvisa passa a analisar a fixação do preço definido, levando em consideração o benefício clínico e o custo do tratamento. Havendo produto assemelhado, se o novo medicamento não trouxer benefício adicional, não poderá custar mais caro do que o medicamento já existente com a mesma indicação. Por tudo isso, o registro na Anvisa mostra-se como condição necessária para atestar a segurança e o benefício do produto, sendo a primeira condição para que o Sistema Único de Saúde possa considerar sua incorporação. Claro que essa não é uma regra absoluta. Em casos excepcionais, a importação de medicamento não registrado poderá ser autorizada pela Anvisa. A Lei no 9.782/99, que criou a Agência Nacional de Vigilância Sanitária (Anvisa), permite que a Agência dispense de "registro" medicamentos adquiridos por intermédio de organismos multilaterais internacionais, para uso de programas em saúde pública pelo Ministério da Saúde. (14).

Apesar do paradigma, as ações continuam a se propagar, com decisões flagrantemente contrárias ao preconizado pelo STF.

Para tentar cessar a sangria, o Conselho Nacional de Justiça (CNJ) criou o Fórum Nacional de Saúde (8) e passou a orientar a magistratura nacional quanto à matéria. Recomendou aos Tribunais a criação de núcleos técnicos especializados para subsidiar e qualificar as demandas e promoveu jornadas com elaboração de enunciados orientativos.

O que se viu, na prática, país afora, foi a baixa adesão dos julgadores aos instrumentos de auxílio disponibilizados, prevalecendo o enfrentando o tema sem a necessária a especialização, até que chega, aos Tribunais Superiores, a análise dos representativos de controvérsias de demandas repetitivas de fornecimento de medicamentos fora dos protocolos, sem registro na Anvisa e tratamentos experimentais.

O primeiro a enfrentar a matéria foi o Superior Tribunal de Justiça (STJ), na análise do Recurso Especial (RE) n 1.657 .156 do Rio de Janeiro (Tema 106), sob a relatoria do Ministro Benedito Gonçalves (9).

A tese fixada definiu, cumulativamente, os seguintes requisitos para fornecimento de 
medicamentos não incorporados em atos normativos do SUS: i) comprovação, por meio de laudo médico fundamentado e circunstanciado expedido por médico que assiste o paciente, da imprescindibilidade ou necessidade do medicamento, assim como da ineficácia, para o tratamento da moléstia, dos fármacos fornecidos pelo SUS; ii) incapacidade financeira de arcar com o custo do medicamento prescrito; e iii) existência de registro do medicamento na Anvisa, observados os usos autorizados pela agência e referidos requisitos (9).

Os parâmetros impostos pelo Tema 106, com respeito à competência técnica do órgão sanitário, sem dúvida, foi um avanço, no que tange a necessidade de processos mais bem instruídos e decisões mais bem fundamentadas. O Judiciário ativista precisaria se valer de respaldo técnico e ir além do risco de morte e direito à vida.

A partir do julgamento do Tema 106, em Pernambuco, deparamo-nos com alguns recentes julgados aplicando a tese fixada. Vejamos:

PROCESSO: 0027147-27.2019.8.17.8201, AUTOR: J. R. D. S., RÉU: ESTADO DE PERNAMBUCO. (...) Na hipótese dos autos, vislumbro que no laudo médico do demandante há a recomendação de uso dos cateteres ali discriminados, para que não ocorra piora do quadro de insuficiência renal. No entanto, aquela prova documental não cuidou de descrever eventual ineficácia dos cateteres fornecidos pelo SUS, o que afigura-se indispensável para a demonstração da plausibilidade do direito invocado. Diante do exposto, indefiro o pedido de tutela provisória. (15)

PROCESSO №: 0802636-60.2019.4.05.0000 - AGRAVANTE: J.C.D.F.L. AGRAVADO: UNIÃO FEDERAL e outro. AGRAVO DE INSTRUMENTO. CONSTITUCIONAL E ADMINISTRATIVO. FORNECIMENTO DE MEDICAMENTOS. UNIÃO FEDERAL. NEOPLASIA MALIGNA DE MAMA (CID10 C-50). TRASTUZUMAB ENTANSINE (KADCYLA). DIREITO CONSTITUCIONAL À SAÚDE (ART. 196 DA CONSTITUIÇÃO FEDERAL). RESP № 1.657.156 (TEMA 106) STJ. REQUISITOS NÃO PREENCHIDOS. AGRAVO NÃO PROVIDO. (...) 3. Relativamente à essencialidade para o tratamento - que é um dos requisitos para a concessão de fármacos não fornecidos pelo SUS de acordo com a tese firmada em recurso repetitivo (Tema 106) - compreende-se como aquele que tenha pretensões curativas ou que comprovadamente melhore a qualidade de vida do paciente, ou que, significativamente, seja capaz de prolongar a expectativa de sobrevida ou reduzir o índice de mortalidade da doença. Se uma medicação tiver uma eficácia terapêutica apenas infimamente superior ao fármaco disponibilizado pelo Estado não deve ser considerada essencial para o tratamento do paciente.

PROCESSO №: 0002338-19.2018.8.17.3250, AUTOR: P. S. D. S. B, RÉU: ESTADO DE PERNAMBUCO. "Contestação (...), na qual o requerido asseverou, (...) a inexistência da hipossuficiência da parte autora e que, 
portanto, não estaria satisfeito um dos requisitos impostos pelo STJ, por ocasião do julgamento do RESp 1.657.156, para fornecimento judicial de medicamentos fora da lista do SUS. (...) Neste ponto, é preciso que se diga que, muito embora o requerente seja da mais tenra idade e, presumidamente, não possua rendimentos, o seu grupo familiar não se configurou como hipossuficiente de forma a justificar a obrigatoriedade do fornecimento do leite pelo SUS. (...) Realizadas tais considerações, (...), aplicando o novo entendimento do STJ, não há como manter o seu deferimento. ISTO POSTO, (...) com fulcro no art. 487, inciso I, do NCPC, ao tempo em que revogo a tutela antecipada anteriormente concedida, JULGO IMPROCEDENTE o pedido deduzido na petição inicial. (16).

PROCESSO №: 0814771-07.2017.4.05.8300, APELANTE: ESTADO DE PERNAMBUCO e outro, APELADO: JOSE ANDERSON DE BARROS SANTOS. (...) 8. O medicamento Nivolumabe não consta como opção terapêutica, pela Anvisa, para melanoma ocular. 9. Nesse contexto, não restou comprovada a eficácia terapêutica do tratamento requerido e a sua essencialidade, pois, Parecer Judicial, inexiste evidência científica conforme atesta o do benefício do uso de Nivolumabe no Melanoma ocular, que se trata de uma condição rara, incurável e de rápida progressão, com poucas opções eficazes para o tratamento (17).

Em pesquisa colacionada nos processos relativos à saúde pública promovidos contra o estado de Pernambuco entre os meses de julho de 2018 e julho de 2019, ainda é incipiente o avanço, mas ele existe e não se pode olvidar de que as conclusões a que chegou o STJ no julgamento desse precedente são vinculantes para todos os órgãos do Poder Judiciário (CPC, art. 927, III, c/c o art. 988, IV) (10).

$\mathrm{Na}$ esteira da necessidade de fixação de parâmetros minimamente razoáveis para deslinde das demandas judiciais de saúde, o STF proferiu os julgamentos dos representativos RE no 657.718 de Minas Gerais (Tema 500 do STF) (11) e RE n 855.178 do Estado de Sergipe (Tema 793 do STF) (12), respectivamente. Vejamos:

Decisão: O Tribunal, apreciando o Tema 500 da repercussão geral, deu parcial provimento ao recurso extraordinário, nos termos do voto do Ministro Roberto Barroso, Redator para o acórdão, vencidos os Ministros Marco Aurélio (Relator) e Dias Toffoli (Presidente). Em seguida, por maioria, fixouse a seguinte tese: "1. O Estado não pode ser obrigado a fornecer medicamentos experimentais. 2. A ausência de registro na Anvisa impede, como regra geral, o fornecimento de medicamento por decisão judicial. 3. É possível, excepcionalmente, a concessão judicial de medicamento sem registro sanitário, em caso de mora irrazoável da Anvisa em apreciar o pedido (prazo superior ao previsto na Lei $n^{0} 13.411 / 2016$ ), quando preenchidos três requisitos: (i) a existência de pedido de registro do medicamento no Brasil (salvo no caso de medicamentos órfãos para doenças raras e ultrarraras);(ii) a existência de registro do medicamento em renomadas agências de 
regulação no exterior; e (iii) a inexistência de substituto terapêutico com registro no Brasil. 4. As ações que demandem fornecimento de medicamentos sem registro na Anvisa deverão necessariamente ser propostas em face da União", vencido o Ministro Marco Aurélio. Ausente, justificadamente, o Ministro Celso de Mello. Plenário, 22.05.2019 (11).

Decisão: Preliminarmente, votou o Ministro Celso de Mello acompanhando o Ministro Edson Fachin na rejeição dos embargos de declaração. Na sequência, o Tribunal, por maioria, fixou a seguinte tese de repercussão geral (Tema 793): "Os entes da federação, em decorrência da competência comum, são solidariamente responsáveis nas demandas prestacionais na área da saúde, e diante dos critérios constitucionais de descentralização e hierarquização, compete à autoridade judicial direcionar o cumprimento conforme as regras de repartição de competências e determinar o ressarcimento a quem suportou o ônus financeiro", nos termos do voto do Ministro Edson Fachin, Redator para o acórdão, vencido o Ministro Marco Aurélio, que não fixava tese. Presidência do Ministro Dias Toffoli. Plenário, 23.05.2019 (12).

Cabe destacar que referidas teses já tiveram suas atas publicadas no Diário de Justiça Eletrônico - DJe de 03/06/2019 e 04/06/2019, respectivamente, sendo se elementar sabença que, nos termos do $\S 11$, do art. 1.035 do CPC, tal fato vale como a publicação do próprio acórdão. Portanto, ditas decisões vinculantes já têm, indubitavelmente, do condão de refletir sobre as demais ações com fundamento na mesma controvérsia.

\section{Considerações finais}

Desde as publicações, seja do acórdão do RE no 1.657 .156 - RJ, seja das atas de julgamentos do RE ํㅜ 657.718 - MG e do RE nº 855.178 - SE, ainda não foi constatada a aplicação maciça das respectivas teses aos processos tramitando perante o Tribunal de Justiça do Estado de Pernambuco e o Tribunal Regional da 5ª Região.

Entretanto, o se espera é a imediata aplicabilidade dos parâmetros preconizados pelos representativos, sobretudo quanto ao direcionamento das ações para a Justiça Federal com a participação premente da União como réu ou co-réu, assim como, no que se refere à incorporação de novas tecnologias, haja a observância dos critérios vinculantes estabelecidos pelo Superior Tribunal de Justiça e pelo Supremo Tribunal Federal, especialmente em relação à aplicação imediata das regras de repartição de competências. 


\section{Referências}

1. Paixão ALS. Reflexões sobre a judicialização do direito à saúde e suas implicações no SUS. Ciênc. saúde coletiva [Internet]. 2019 June [cited 2019 Aug 29]; 24(6): 2167-2172. Available from: http://www.scielo.br/scielo.php?script=sci_arttext\&pid=\$1413-8123201900 0602167\&lng=en.

2. Catanheide ID, Lisboa ESS, Luis EPF. Características da judicialização do acesso a medicamentos no Brasil: uma revisão sistemática. Physis: Revista de Saúde Coletiva [online]. 2016, v. 26, n. 4, pp. 1335-1356. Disponível em: https://doi.org/10.1590/S010373312016000400014 [Acesso 29 ago. 2019].

3. Tabosa TMS. A judicialização da saúde no estado de Pernambuco: análise do impacto das decisões judiciais sobre o orçamento público. Recife, 2010. 67 f. Dissertação (mestrado) - Universidade Federal de Pernambuco. CCSA, Economia, 2010.

4. Moraes VMS. Análise dos gastos com ações judiciais na Secretaria de Saúde do Estado de Pernambuco no ano de 2014/Vânia Maria Silva de Moraes. - 2016. 53 folhas: il. $30 \mathrm{~cm}$. Dissertação (Mestrado em Gestão e Economia da Saúde) - Universidade Federal de Pernambuco, CCSA, 2016.

5. Ministério da Saúde (Brasil). Portarias GM/MS no 874, de 16 de maio de 2013. Institui a Política Nacional para a Prevenção e Controle do Câncer na Rede de Atenção à Saúde das Pessoas com Doenças Crônicas no âmbito do Sistema Único de Saúde (SUSS). Diário Oficial da União 17 maio 2013; Seção 1.

6. Schulze CJ. A judicialização da saúde no século XXI. 1를 Ed. Porto Alegre: Verbo Jurídico, 2018.

7. Brasil. Lei o․ 9.782, de 26 de janeiro de 1999. Define o Sistema Nacional de Vigilância Sanitária, cria a Agência Nacional de Vigilância Sanitária, e dá outras providências. Diário Oficial da União, 27 jan. 1999; p1.

8. Conselho Nacional de Justiça (Brasil). Recomendação № 31, de 30 de março de 2010. Recomenda aos Tribunais a adoção de medidas visando a melhor subsidiar os magistrados e demais operadores do direito, para assegurar maior eficiência na solução das demandas judiciais envolvendo a assistência à saúde. DJ-e 07 abr 2010; p. 4-6. Disponível em: http://www.cnj.jus.br/atos-administrativos/atos-da-presidencia/322-recomendacoes-doconselho/12113-recomendacao-no-31-de-30-de-marco-de-2010 [Acesso em 29 jul. 2019].

9. Recurso Especial oo 1.657.156 - RJ (2017/0025629-7). Disponível em: https://ww2.stj.jus.br/processo/revista/documento/mediado/?componente=ITA\&sequencial= 1641175\&num_registro=201700256297\&data=20180504\&formato=PDF [Acesso em 29 jul. 2019].

10. BRASIL. Lei no 13.105, de 16 de março de 2015. Código de Processo Civil, Brasília, DF, mar 2015. Disponível em: http://www.planalto.gov.br/ccivil_03/_ato2015-2018/2015/ 
lei/l13105.htm [Acesso em 14 abr. 2019].

11. Recurso Extraordinário no 657.718 - MG. Disponível em: https://portal.stf.jus.br/ processos/detalhe.asp?incidente $=4143144$ [Acesso em 29 jul. 2019].

12. Recurso Extraordinário no 855.178 - SE. Disponível em: http://www.stf.jus.br /portal/jurisprudenciaRepercussao/verAndamentoProcesso . asp?incidente $=4678356 \&$ numer oProcesso $=855178 \&$ classeProcesso $=R E \&$ numeroTema $=793$ [Acesso em 29 jul. 2019].

13. STF - STA: 175 CE, Relator: Min. PRESIDENTE, Data de Julgamento: 16/06/2009, Data de Publicação: DJe-117 DIVULG 24/06/2009 PUBLIC 25/06/2009.

14. STF - SS: 3989 PI, Relator: Min. PRESIDENTE, Data de Julgamento: 07/04/2010, Data de Publicação: DJe-066 DIVULG 14/04/2010 PUBLIC 15/04/2010.

15. Pernambuco. 1ํ Juizado Especial da Fazenda Pública da Capital. Processo 002714727.2019.8.17.8201.

16. Pernambuco. Tribunal Regional Federal da 5 $5^{\underline{a}}$ Região. AGTR 080263660.2019.4.05.0000. Relator: Des. Federal Edilson Nobre, Data de Julgamento: 30/05/2019.

17. Pernambuco. Tribunal Regional Federal da 5ํㅗ Região. AC 0814771-07.2017.4.05.8300. Relator: Des. Federal Edilson Nobre, Data de Julgamento: 17/05/2019.

Como citar esse artigo: recursos repetitivos pelos Tribunais Superiores. Cadernos Ibero-Americanos de Direito Sanitário. 2019 jul./set.; 8(3): 102-111.

http://dx.doi.org/10.17566/ciads.v8i3.552 